\begin{tabular}{|c|c|c|c|}
\hline \multirow[b]{2}{*}{ Topic } & \multicolumn{2}{|c|}{$\begin{array}{l}\text { Percentage }(\text { No) performing to } \\
\text { acceptable standard } \\
(\geqslant 60 \% \text { in multiple choice paper })\end{array}$} & \multirow[b]{2}{*}{$\mathrm{p}$ Value } \\
\hline & 1990 & 1985 & \\
\hline \multicolumn{4}{|l|}{ Multiple choice paper } \\
\hline General topics relating to cardiopulmonary resuscitation (three questions) & $73(23)$ & 73 & $0 \cdot 8762$ \\
\hline Ventilation (two questions) & $48(15)$ & 23 & 0.514 \\
\hline Management of ventricular fibrillation (one question) & $96(30)$ & 33 & 0.0001 \\
\hline Management of asystole (one question) & $58(18)$ & 10 & 0.0001 \\
\hline Management of electromechanical dissociation (one question) & $80(25)$ & 47 & 0.0086 \\
\hline Recognition and management of general arrhythmia (two questions) & $74(23)$ & & \\
\hline \multicolumn{4}{|l|}{ Practical examination } \\
\hline External cardiac massage and mouth to mouth ventilation & $48(15)$ & 55 & 0.5992 \\
\hline Ventilation with a pocket mask & $10(3)$ & & \\
\hline Ventilation with Ambubag & $29(9)$ & & \\
\hline Intubation & $22(7)$ & 34 & \\
\hline
\end{tabular}

Ventilation with Ambubag after 12 months. ${ }^{5}$ All but one of our doctors had received training in resuscitation during their clinical attachment to the accident and emergency department, but this had been 18-24 months before their graduation. Students are encouraged to attend cardiac arrest calls in the hospital but get little opportunity to practise skills in an emergency. Regular refresher sessions should be held, but how often these should be attended remains open to debate. We found that the doctors could not ventilate the manikin with either the Ambubag or the pocket mask; this skill seems to have been overlooked in teaching programmes and requires emphasis.

Only seven house officers had adequate skills at intubation. Few could identify and use basic equipment, and few had any concept of the sizes of endotracheal tubes. The Resuscitation Council's guidelines make no recommendations that medical students should be taught techniques of intubation for resuscitation, and although house officers may not be required to intubate a patient in an emergency, they should be able to identify basic equipment as they might have to help a skilled operator.

1 Casey WF. Cardiopulmonary resuscitation: a survey of standards among junior hospital doctors. I $R$ Soc Med 1984;77:921-4.

2 Skinner DV, Camm AJ, Miles S. Cardiopulmonary resuscitation skills of preregistration house officers. BMf 1985;290:1549-50.

3 Baskett PJF. Resuscitation needed for the curriculum? BMf 1985;290:1531-2.

4 Royal College of Physicians. Report: resuscitation from cardiopulmonary arrest: training and organization. $f R$ Coll Physicians Lond 1987;21:175-82.

5 Curry L, Gass D. Effects of training in cardiopulmonary resuscitation on competence and patient outcome. Can Med Assoc f 1987;137:491-6.

(Accepted 8 fanuary 1991)

\section{Beclomethasone inhalation decreases serum osteocalcin concentrations}

\author{
Ellen M Pouw, Mark F Prummel, \\ Hans Oosting, Carel M Roos, Erik Endert
}

Academic Medical Centre, $1105 \mathrm{AZ}$ Amsterdam, The Netherlands

Ellen M Pouw, MD, registrar, department of internal medicine

Mark F Prummel, MD, internist

Hans Oosting, PHD, biostatistician

Carel M Roos, MD, chest physician

Erik Endert, MSC, clinical chemist

Correspondence to:

Dr M F Prummel

Department of

Endocrinology, F5-258,

Academic Medical Centre,

Meibergdreef $9,1105 \mathrm{AZ}$

Amsterdam, The

Netherlands.

BMY 1991;302:627-8
Inhaled corticosteroids have proved efficacious in treating bronchial asthma, and severe systemic side effects seem to be rare, even with high dosages.' Because of this combination of efficacy and tolerability the indications for their use are widening and higher dosages are being prescribed.

Despite the lack of adrenal suppression in patients on high dose $(1.5-2.0 \mathrm{mg} /$ day $)$ inhalation corticosteroids skin thinning and purpura were found to occur more often in such patients. ${ }^{2}$ A severe complication of long term treatment with oral corticosteroids is osteoporosis, which is mainly caused by depression of bone formation. Serum osteocalcin, which is produced by the osteoblasts, seems to be a protein produced exclusively by bone forming cells, ${ }^{3}$ and it has been shown that the use of oral corticosteroids results in lowered concentrations of serum osteocalcin. ${ }^{+}$

We aimed to determine the effect of beclomethasone inhalation on osteocalcin concentrations in healthy volunteers.

\section{Subjects, methods, and results}

Eight healthy volunteers (three premenopausal women and five men; mean (SD) age $32 \cdot 6(8 \cdot 2)$ years, range 26-51) were studied; they were not taking any drugs. After supervised training with a placebo device, all subjects used beclomethasone inhalation for two weeks in four doses of $500 \mu \mathrm{g}$ a day. They were studied before start of treatment (day 1), after one and two weeks of treatment (days 8 and 15), and one and two weeks after stopping (days 22 and 29). Because it has been reported that osteocalcin has a diurnal variation, blood was drawn hourly from 0900 until 1500 through an indwelling catheter. During treatment (days 8 and 15) beclomethasone was given just after a blood sample had been drawn at 0900 and 1400 hours.
Osteocalcin concentrations were determined by a commercial radioimmunoassay (IncStar, Stillwater, Minnesota); interassay and intra-assay variations were $5 \cdot 4 \%$ and $6 \cdot 1 \%$ respectively. A multivariate analysis for repeated measurements was used to analyse the data, and the within subject covariance matrix was assumed to be of the compound type. The likelihood ratio test was used to test for a treatment effect and for a time effect (for example, diurnal variation) and to find a model consistent with the observed data (figure).

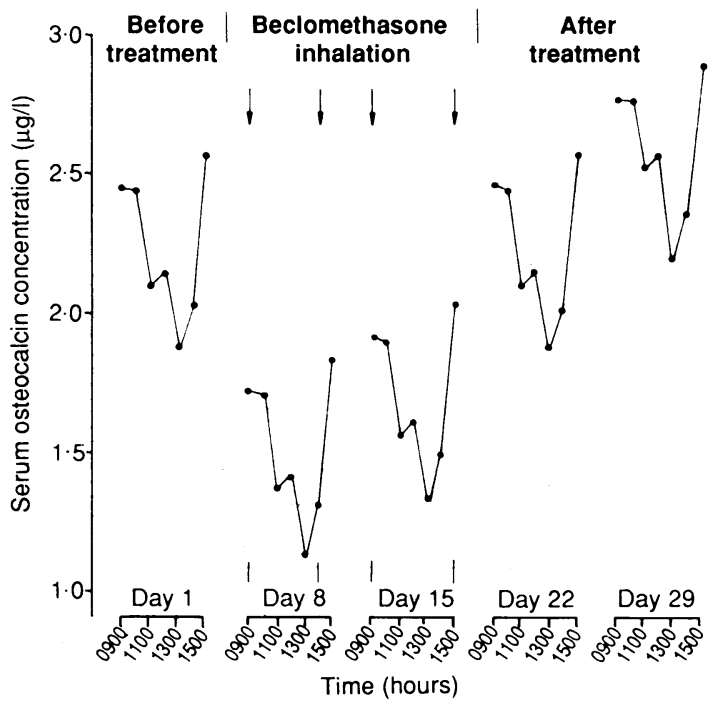

Osteocalcin concentrations during daytime in eight healthy volunteer before (day 1), during (days 8 and 15), and after (days 22 and 29 treatment with inhaled beclomethasone. Arrows indicate timing of inhalation. Curves represent model constructed with likelihood ratio test and show significant diumal variation on all days $(p=$ 0.041). Effect of taking inhaled beclomethasone: day $8 v$ day 1 , $p<0.001 ;$ day 15 v day $1, p<0.001 ;$ day 8 v day $15, p>0.05$

On days 8 and 15 a treatment effect was clearly seen: serum osteocalcin concentrations decreased a mean of $0.73 \mu \mathrm{g} / \mathrm{l}$ during inhalation of beclomethasone $(\mathrm{p}<0.001)$. No additional effect was seen on day 15 . On days 22 and 29 osteocalcin values returned to pretreatment levels. In addition, a time effect (diurnal variation) was observed, with troughs around noon $(p=0.041)$; this was not affected by beclomethasone inhalation. 


\section{Comment}

During treatment with inhaled beclomethasone the osteocalcin concentrations decreased, as has been observed in patients taking oral corticosteroids. This might imply that during beclomethasone treatment bone formation is depressed, which could result in osteoporosis in the long run.

In our pilot study we investigated healthy subjects who used a high dose of beclomethasone for a short period of time. Whether osteocalcin concentrations are also lowered in asthmatic patients treated with lower doses of beclomethasone over the long term is unknown at present. This is not unlikely, however-firstly, because the resorption of the drug might be better in patients than in healthy subjects and, secondly, because osteocalcin remained depressed during long term treatment of patients with oral corticosteroids. ${ }^{+}$There- fore a longitudinal study measuring serum osteocalcin concentrations and bone mineral density in newly diagnosed patients with asthma taking inhaled corticosteroids seems warranted.

We thank Mrs W Norder-Paulides for technical assistance.

1 Barnes PJ. A new approach to the treatment of asthma. $N$ Engl $f$ Med 1989;321:571-25

2 Capewell S, Reynolds S, Shuttleworth D, Edwards C, Finlay AY. Purpura and dermal thinning associated with high dose inhaled corticosteroids. $B M$ 1990;300:1548-51.

3 Brown JP, Delmas PD, Malaval L, Edouard C, Chapuy MC, Meunier P]. Serum bone Gla-protein: a specific marker for bone formation in postmenopausal osteoporosis. Lancet 1984;i:1091-3.

4 Prummel MF, Wiersinga WM, Lips P, Sanders GTB, Sauerwein HP. The course of biochemical parameters of bone turnover during treatment with corticosteroids. F Clin Endocrinol Metab 1991;72:382-6.

5 Gundberg CM, Markowitz ME, Mizruchi M, Rosen JF. Osteocalcin in human serum: a circadian rhythm. F Clin Endocrinol Metab 1985;60:736-9.

(Accepted 12 January 1991)
Harris Birthright Research Centre for Fetal Medicine, Department of Obstetrics and Gynaecology, King's College School of Medicine and Dentistry, London SE5 8RX

J G Thorpe-Beeston, MRCOG, research registrar K H Nicolaides, MRCOG, consultant

M R C Human Genetics Unit, Western General Hospital, Edinburgh

C M Gosden, PHD, professor

Department of Medicine, King's College School of Medicine and Dentistry

A M McGregor, MD, professor

Correspondence to: $\mathrm{Mr}$ Nicolaides.

BMF 1991;302:628

\section{Thyroid function in fetuses with chromosomal abnormalities}

\section{J G Thorpe-Beeston, K H Nicolaides, C $M$ Gosden, A M McGregor}

In children with Down's syndrome the incidence of thyroid disorders is reported to be $6 \%$, which is 28 times higher than that expected in the general population. ${ }^{1}$ Evidence suggests that early diagnosis and effective treatment may not only improve the physical wellbeing of such infants but also have an appreciable impact on intellectual function. ${ }^{2}$ We aimed at determining whether there is in utero evidence of thyroid dysfunction in fetuses with chromosomal abnormalities.

\section{Methods and results}

Using radioimmunoassay, we measured serum thyroid stimulating hormone, free and total thyroxine, and triiodothyronine concentrations in umbilical venous blood samples obtained by cordocentesis from 15 fetuses with chromosomal abnormalities (trisomy 21 (five), trisomy 18 (five), trisomy 13 (one), triploidy (two), and Klinefelter's syndrome (two)) at 17-36 weeks' gestation. ${ }^{34}$ The indication for cordocentesis was fetal karyotyping after fetal malformations had been detected by ultrasonography. Informed consent was obtained from the mothers, and the project was approved by the hospital ethical committee.

In the five fetuses with Down's syndrome, two of the five with trisomy 18 , and one of the two with triploidy thyroid stimulating hormone concentration was above the 95 th centile of the reference range (figure). In all 15 fetuses, however, thyroid hormone concentrations were within the reference ranges, and the mean values were not significantly different from the normal means for gestation (free triiodothyronine concentration: mean difference $=0 \cdot 118 \mathrm{SD}, t=0 \cdot 30$; free thyroxine: $-0.249 \mathrm{SD}, t=0.61$; total triiodothyronine: $0.705 \mathrm{SD}$, $t=2 \cdot 87$; total thyroxine: $0 \cdot 225 \mathrm{SD} t=0 \cdot 56$ ).

\section{Comment}

The high thyroid stimulating hormone in some fetuses with a chromosomal abnormality, particularly those with trisomy 21 , may be an early manifestation of relative hypothyroidism. Animal studies have

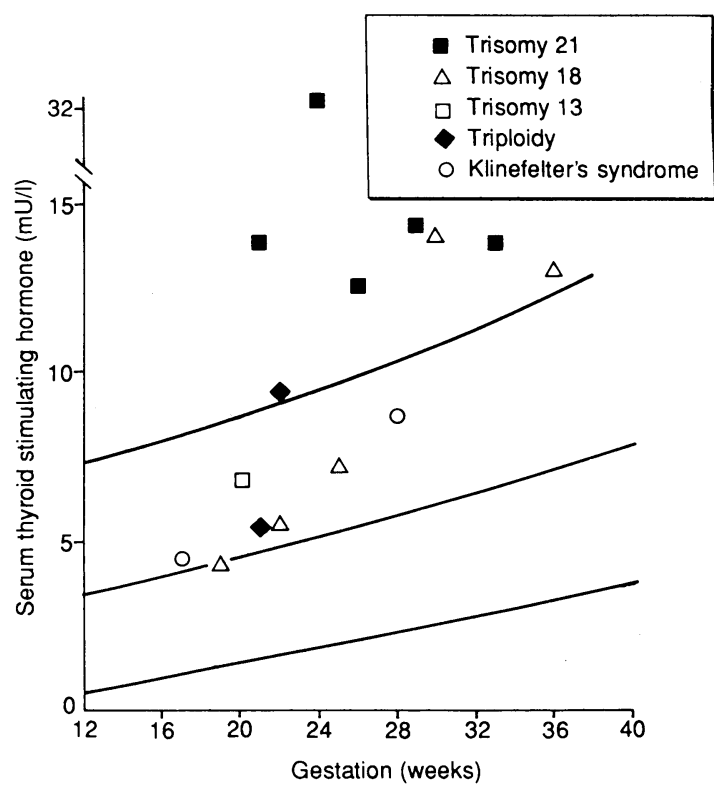

Serum thyroid stimulating hormone concentration in 15 fetuses with chromosomal abnormalities plotted on reference range (mean values and 5 th and 95 th centiles $)^{4}$ for gestation

suggested that thyroid hormones have a critical role in the growth and functional development of the brain. In humans congenital hypothyroidism is associated with appreciable abnormalities in physical and neurological development, manifested at its extreme by cretinism. Prompt postnatal treatment usually prevents these adverse sequelae. Intrauterine hypothyroidism of early onset, as documented in some fetuses with chromosomal abnormalities, could, however, result in irreversible brain damage and may be one of the underlying causes of mental handicap in such infants. The extent to which intrauterine hormone supplementation would reduce impaired neurological development remains to be determined.

1 Cutler AT, Benezra-Obeiter R, Brink SJ. Thyroid function in young children with Down syndrome. Am $\mathcal{F}$ Dis Child 1986;140:479-83.

2 Pueschel SM, Pessullo JC. Thyroid dysfunction in Down syndrome. Am $\mathcal{J}$ Dis Child 1985;139:636-9.

3 Nicolaides KH, Soothill PW, Rodeck CH, Campbell S. Ultrasound-guided sampling of the umbilical cord and placental blood to assess fetal well-being. Lancet 1986; ;: 1065-7.

4 Thorpe-Beeston JG, Nicolaides KH, Felton CV, Butler J, McGregor AM. Maturation of the fetal thyroid and increasing secretion of thyroid stimulating hormone. N Engl f Med 1991;324:532-6.

5 de Escabor GM, Obregon MJ, del Rey FE. Fetal and maternal thyroid hormones. Horm Res 1987;26:12-27.

(Accepled 8 fanuary 1991) 